\title{
PHẪU THUẬT NỘI SOI TOÀN BỘ TẠO HÌNH THÀNH BÊN NHĨ TRÁI Ở BỆNH NHÂN U NHẦY NHĨ TRÁI PHỨC TẠP
}

\section{TÓM TẮT}

Phẫu thuật nội soi toàn bộ đã được ứng dụng tại một số trung tâm trên thế giới để điều trị u nhầy nhĩ, tuy nhiên chỉ định vẫn còn hạn chế, nhất là trong những trường hợp u phức tạp.

Ca lâm sàng: Bệnh nhân nữ, 59 tuổi có khối u nhầy nhĩ trái lớn, cuống rộng bám vào vách liên nhĩ, thành sau và thành bên nhĩ trái,đã được phẫu thuậtnội soi toàn bộ cắt u triệt để và tạo hình lại thành nhĩ trái.

Kết luận: Những trường hợp u nhầy nhĩ có giải phẫu phức tạp vẫn có thể được điều trị triệt để, an toàn bằng phẫu thuật nội soi toàn bộ với ê-kíp phẫu thuật có kinh nghiệm.

Tù khóa: u nhầy nhĩ trái, phẫu thuật nội soi toàn bộ, tạo hình nhĩ trái

\section{I. ĐẠTT VẤN ĐỀ}

U nhầy trong tim là dạng u lành tính, nguyên phát thường gặp nhất trong số các khối u có nguồn gốc tại tim[1].Mặc dù là u lành tính tuy nhiên $\mathrm{u}$ nhầy có thể gây ra những biến chứng tắc mạch hệ thống nặng nề như đột quỵ và nhồi máu cơ tim. Trong khoảng 10 năm trở lại đây, phẫu thuật nội soi toàn bộ đã được ứng dụng tại một số trung tâm lớn trên thế giới để điều trị bệnh u nhầy nhĩ [2-4].Mặc dù vậy vẫn có những chống chỉ định tương đối của phương pháp này như: $\mathrm{u}$ nhầy khổng lồ, $\mathrm{u}$ nhầy có cuống rộng bám vào những vị trí khó như thành sau, thành bên nhĩ trái, trần nhĩ trái, chân tĩnh mạch phổi,... Chúng tôi trình bày dưới đây một ca lâm sàng u nhầy nhĩ trái lớn, cuống rộng đã được phẫu thuật nội soi toàn bộ không robot hỗ trợ cắt $\mathrm{u}$ triệt để và tạo hình lại thành nhĩ trái.

\section{Đặng Quang Huy*, Nguyễn Minh Ngoc**}

\section{CA LÂM SÀNG}

Bệnh nhân nữ, 59 tuổi, chưa phát hiện tiền sử bệnh lý tim mạch trước đây. Nhập viện vì đau ngực, khó thở khi gắng sức.Trên siêu âm tim và phim chụp CVLT có hình ảnh khối u trong nhĩ trái kích thước $38 \times 24 \mathrm{~mm}$, mật độ đồng nhất, ranh giới rõ, ít di động, cuống $\mathrm{u}$ rộng bám vào vách liên nhĩ, thành sau và thành bên nhĩ trái đến sát chân tĩnh mạch phổi dưới phải. Chức năng tim và các van tim hoạt động bình thường.Các thăm dò, xét nghiêm khác không có kết quả bất thường.
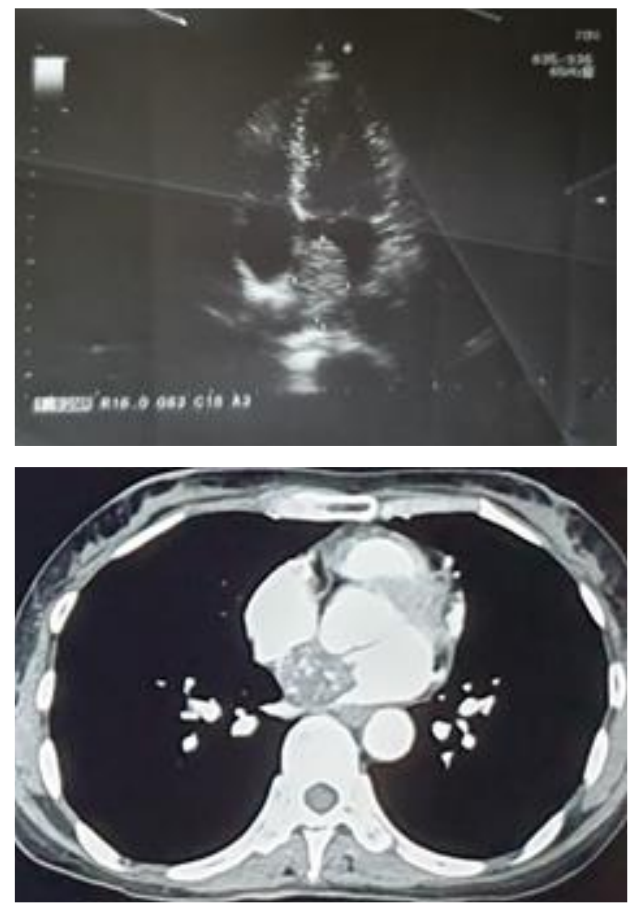

Hình 1: Hình ảnh khối u trên siêu âm tim và chup CLVT

\footnotetext{
* Trung tâm phẫu thuật tim mạch, bệnh viện Tim Hà Nội Nguời chịu trách nhiệm khoa học: ThS. Đặng Quang Huy Ngày nhận bài: 01/07/2019 - Ngày Cho Phép Đăng: 20/07/2019 Phản Biện Khoa họ: PGS.TS. Đặng Ngọc Hùng GS.TS. Lê Ngoc Thành
} 
Bệnh nhân đã được hội chẩn và chỉ định mạch (ĐM) đùi gián tiếp qua đoạn mạch số 8 (B. phẫu thuật nội soi toàn bộ để cắt $u$ nhầy.Trong Braun Uni-Graft), và đặt ống thôngtĩnh mạch chủ mổ, bệnh nhân được gây mê nội khí quản, kê tư (TMC) trên và dưới qua tĩnh mạch (TM) cảnh thế nghiêng trái 30 độ.Thiết lập tuần hoàn ngoài trong phải và TM đùi phải theo phương pháp cơ thể qua mạch ngoại vi: đặt ống thôngđộng Seldinger.

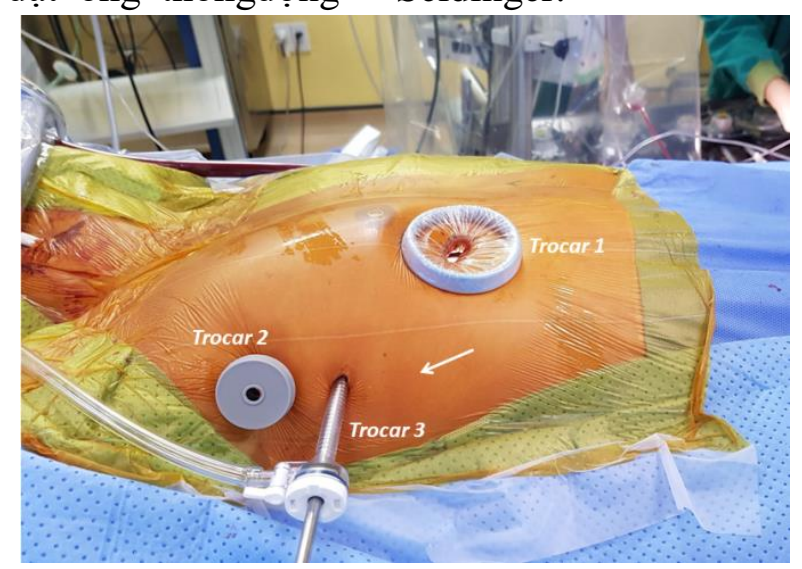

Hình 2: Thiết lập các lô̂ trocar qua thành ngưc. Trocar 1 cho tay làm việc chính, trocar 2 cho tay làm việc phu và clamp ĐMC, trocar 3 cho camera, và trocar 4 (vị trí đầu mũi tên trắng) cho đưòng hút nhĩ trái

Thiết lập 4 lỗ trocar trên thành ngực bên phải, bao gồm: 01 trocar $15 \mathrm{~mm}$ tại KLS $\mathrm{V}$ đường nách trước là tay làm việc chính; 01 trocar $5 \mathrm{~mm}$ tại KLS IV đường nách giữa cho Clampđộng mạch chủ (ĐMC); 01 trocar $5 \mathrm{~mm}$ tại $\mathrm{KLS} \mathrm{V}$ đường nách giữa cho camera nội soi; và 01 trocar $5 \mathrm{~mm}$ tại KLS VI đường nách giữa cho dẫn lưu tim trái.

$\mathrm{CO} 2$ được bơm vào khoang màng phổi với lưu lượng 01 lít/phút. Chạy máy tuần hoàn ngoài cơ thể (THNCT) toàn bộ lưu lượng. Luồn dây thắt $\mathrm{TM}$ chủ trên và $\mathrm{TM}$ chủ dưới. Đặt kim gốc động mạch chủ. Cặp ĐM chủ. Bảo vệ cơ tim xuôi dòng bằng dung dịch Custodiol. Tiếp cận và bộc lộ khối u nhầy qua 02 đường mở: đường mở dọc nhĩ phảisau đó mở vách liên nhĩ, và đường mở trực tiếp vào nhĩ trái qua rãnh liên nhĩ. Thăm dò thấy khối u dạng u nhầy nằm trong nhĩ trái, kích thướcu lớn, khoảng 30x40mm, cuống u rộng, bám vào 1 phần vách liên nhĩ, lan sang thành bên và thành sau nhĩ trái và lan đến chân tĩnh mạch phổi dưới phải.Chúng tôi đã tiến hành cắt bỏ toàn bộ thành nhĩ trái chứa u nhầy, cách chân u khoảng $5 \mathrm{~mm}$. Khối u được đưa ra ngoài bằng túi bệnh phẩm nội soi, đưa qua lỗ trocar chính. Kiểm tra trong nhĩ trái và thất trái không còn tổ chức $u$. Kiểm tra giải phẫu và chức năng van hai lá bình thường.

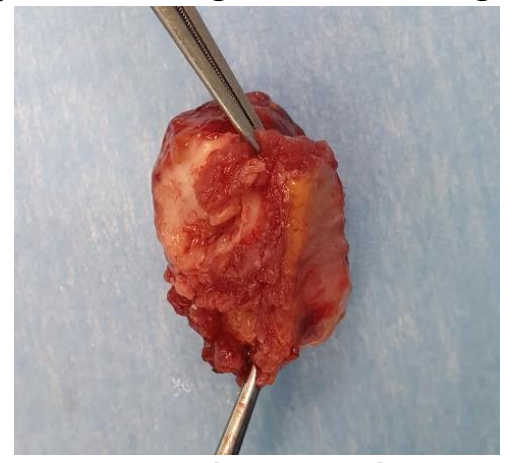

Hình 3: Khối u có cuống rộng 
Tiến hành tạo hình lại thành sau và thành bên nhĩ trái: thành sau được đóng trực tiếp bằng chỉ Prolene 4-0 (Johnson \& Johnson Medical), khâu vắt 2 lớp (hình $4 \mathrm{~b}$ ), thành bên được tạo hình bằng miếng vá màng tim sinh học (LeMaitre XenoSure), khâu vắt bằng chỉ Prolene 5-0 (hình $4 \mathrm{c}$ ).
Đóng lại vách liên nhĩ, đường mở nhĩ trái và nhĩ phải. Thả cặp ĐM chủ cho tim đập lại, nhịp xoang đều. Kiểm tra cầm máu, đặt các dẫn lưu, rút các cannula động tĩnh mạch và đóng các vết mổ. Thời gian cặp $\mathrm{ĐM}$ chủ 126 phút, thời gian chạy máy THNCT 225 phút.

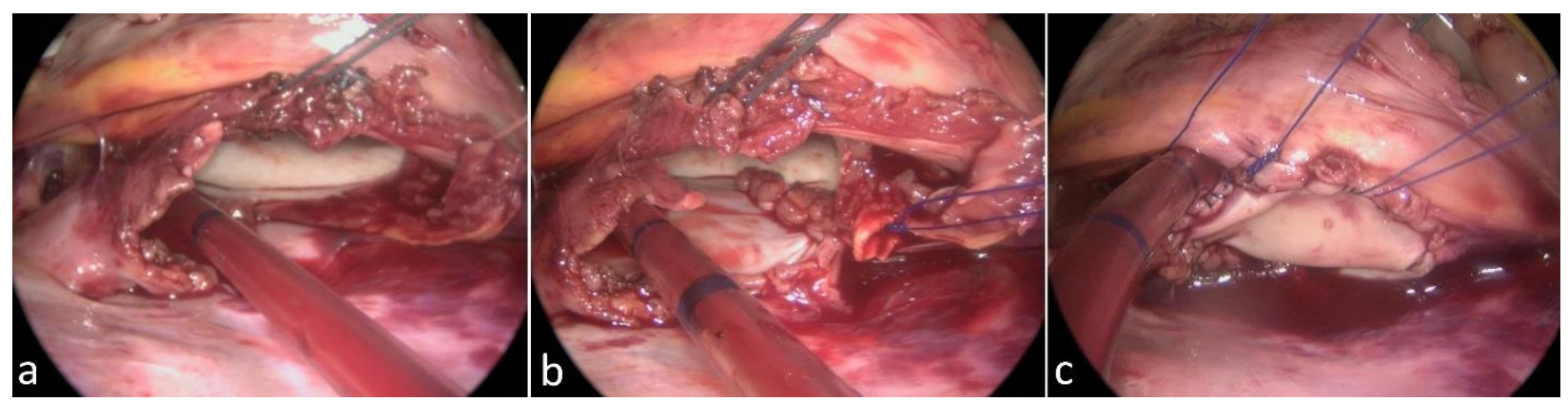

Hình 4: (a)cắt triệt để cuống $u$, thành bên và thành sau nhĩ trái; (b)khâu đóng thành sau nhĩ trái; (c) tạo hình thành bên nhĩ trái bằng miếng màng tim

Sau phẫu thuật, bệnh nhân được rút ống nội khí quản sau $12 \mathrm{~h}$, không có biến chứng. Bệnh nhân nằm hồi sức 2 ngày và ra viện sau 7 ngày. Siêu âm sau mổ không còn u tồn lưu, chức năng tim và các van tim bình thường. Kết quả giải phẫu bệnh khối u là u nhầy lành tính. Khám lại sau 3 tháng không thấy u tái phát.

\section{BÀN LUẬn}

U nhầy trong nhĩ trái chiếm $80 \%$ các trường hợp u nhầy trong tim, trong đó $95 \%$ các trường hợp khối u có cuống bám vào vách liên nhĩ. 5\% trường hợp còn lại cuống $\mathrm{u}$ bám vào các vị trí khác như trần nhĩ, tiểu nhĩ, thành sau nhĩ trái hoặc tĩnh mạch phổi[1, 5].

C.Gao và cs đã báo cáo 19 trường hợp được phẫu thuật cắt u bằng phương pháp nội soi toàn bộ có robot hỗ trợ (hệ thống $\mathrm{Da}$ Vinci) với kết quả tốt, không có tử vong và biến chứng[6].Trong báo cáo củaJ. Schilling và cs, tác giả đãso sánh17 trường hợp được cắt $\mathrm{u}$ bằng nội soi toàn bộ có robot hỗ trợ với 34 trường hợp được cắt $u$ bằng phẫu thuật đường giữa xương ức, kết quả điều trị là không khác biệt giữa hai nhóm, tuy nhiên nhóm bệnh nhân được phẫu thuật nội soi có thời gian thở máy và thời gian nằm viện ngắn hơn[7].Tác giả Dang $\mathrm{Q}$.H. và $\mathrm{cs}$ đã báo cáo 1 trường hợp phẫu thuật cắt $u$ nhầykhổng lồ thành công bằng phương pháp nội soi toàn bộ không robot hỗ trợ[8].Ủu điểm của phương pháp phẫu thuật nội soi toàn bộ bên cạnh vết mổ thẩm mỹ còn là hạn chế những ảnh hưởng của việc cưa xương ức, giảm thời gian nằm viện và giảm tác động tới chất lượng cuộc sống sau mổ. Theo báo cáo của $\mathrm{M}$. Yang và cs, chỉ số chất lượng cuộc sống trong 30 ngày đầu sau phẫu thuật của nhóm bệnh nhân được phẫu thuật cắt $\mathrm{u}$ nội soi tốt hơn so với nhóm mổ mở, và bệnh nhân phẫu thuật nội soi có thể sớm trở lại sinh hoạt bình thường hơn[9]. 


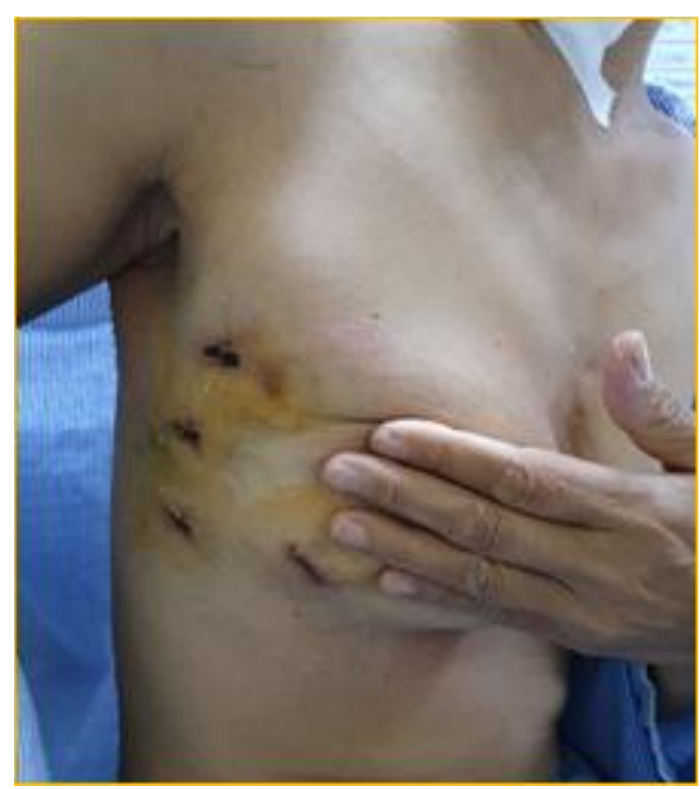

Hình 5: Sẹo mổ của bệnh nhân

Tuy nhiên, trong các nghiên cứu trên, chủ yếu các bệnh nhân được phẫu thuật cắt bỏ u nhầy ít xâm lấn là những trường hợp $u$ nhầy nhĩ phải hoặc nhĩ trái có cuống khu trú bám ở vách liên nhĩ. Đối với những trường hợp cuống $\mathrm{u}$ bám vào những vị trí phức tạp, có thể xử trí bằng hai phương pháp: Phương pháp cắt bỏ triệt để thành nhĩ sau đó tạo hình lại và phương pháp bảo tồn thành nhĩ trái, chỉ lấy bỏ cuống u tới lớp cơ thành nhĩ. Tuy nhiên, về mặt lý thuyết, phương pháp này có nguy cơ tái phát u cao hơn, nhất là trong trường hợp cuống $\mathrm{u}$ rộng. Trong báo cáo của tác giả $\mathrm{C}$. Gao và cs có báo cáo 2 trường hợp cuống $\mathrm{u}$ bám vào thành sau nhĩ trái, hai trường hợp này đã được phẫu thuật cắt bỏ cuống $u$ và bảo tồn thành nhĩ trái[6].Hiện nay chúng tôi chưa thấy có báo cáo nào về phẫu thuậtnội soi toàn bộ cắt bỏ u nhầy trong nhĩ trái và tạo hình lại thành tự do nhĩ trái.

Đối với bệnh nhân trong báo cáo này, chúng tôi lựa chọn phương pháp cắt $u$ triệt để, bao gồm cả cuống $u$ và thành nhĩ trái. Do cuống $u$ bám rộng, phần thành nhĩ trái phải cắt bỏ lớn nên chúng tôi sử dụng miếng vá màng tim sinh học để tạo hình lại thành bên nhĩ trái. Thành sau nhĩ trái có lớp cơ dày và di động nên chúng tôi đóng trực tiếp bằng khâu vắt 02 lớp. Phương pháp này giúp giảm nguy cơ chảy máu sau mổ và không làm ảnh hưởng đến kích thước của nhĩ trái.Tuy nhiên đây là một thách thức về mặt kỹ thuật, đặt biệt là với mổ nội soi toàn bộ. Mọi thao tác cắt $u$ và tạo hình nhĩ trái đều được thực hiện với cả 2 tay phẫu thuật đi qua lỗ trocar chính $15 \mathrm{~mm}$. Kết quả sau phẫu thuật tốt, không có biến chứng chảy máu và rối loạn nhịp. Kích thước nhĩ trái đo trên siêu âm tim trước và sau mổ không có sự khác biệt.

\section{KẾT LUẬN}

Phẫu thuật nội soi toàn bộ không robot hỗ trợđể điều trị u nhầy nhĩ trái là phương pháp an toàn, hiệu quả, và có nhiều ưu điểm.Đối với ê-kíp phẫu thuật nội soi có kinh nghiệm, có thể mở rộng chỉ địnhphẫu thuật nội soi toàn bộ cho những trường hợp phức tạp như khối u kích thước lớn, cuống bám rộng. 


\section{TÀI LIỆ THAM KHẢO}

1. Castillo, J.G. and G. Silvay, Characterization and management of cardiac tumors. Semin Cardiothorac Vasc Anesth, 2010. 14(1): p. 6-20.

2. Gao, C., et al., Totally robotic resection of myxoma and atrial septal defect repair. Interact Cardiovasc Thorac Surg, 2008. 7: p. 947-50.

3. Gao, C., et al., Excision of atrial myxoma using robotic technology. The Journal of Thoracic and Cardiovascular Surgery. 139(5): p. 1282-1285.

4. Onan, B., et al., Robotic resection of giant left ventricular myxoma causing outflow tract obstruction. J Card Surg, 2017. 32(5): p. 281-284.

5. Cottini, M., et al., Posterior wall as atypical localization of left atrial myxoma :
Diagnosis and management. Herz, 2017. 42(4): p. 390-394.

6. Gao, C., et al., Excision of atrial myxoma using robotic technology. J Thorac Cardiovasc Surg, 2010. 139(5): p. 1282-5.

7. Schilling, J., et al., Robotic excision of atrial myxoma. J Card Surg, 2012. 27(4): p. 423-6.

8. Dang, Q.H., et al., Totally Endoscopic Resection of Giant Left Atrial Myxoma Without Robotic Assistance. Innovations (Phila), 2018. 13(2): p. 136-139.

9. Yang, M., et al., Comparison of postoperative quality of life for patients who undergo atrial myxoma excision with robotically assisted versus conventional surgery. J Thorac Cardiovasc Surg, 2015. 150(1): p. 152-7. 